\title{
Prevalence of Human Immunodeficiency Virus in Tuberculosis Positive Patients in General Hospital Onitsha, Nigeria
}

\author{
Onuorah Samuel $^{1, *}$, Obika Ifeanyi ${ }^{2}$, Orji Michael $^{1}$ \\ ${ }^{1}$ Department of Applied Microbiology and Brewing, Nnamdi Azikiwe University Awka, Nigeria \\ ${ }^{2}$ Department of Zoology, Nnamdi Azikiwe University Awka, Nigeria
}

Copyright (C) 2015 by authors, all rights reserved. Authors agree that this article remains permanently open access under the terms of the Creative Commons Attribution License 4.0 International License

\begin{abstract}
Tuberculosis (TB) and human immunodeficiency virus (HIV) co-infection is a major challenge in tuberculosis prevention and control. The prevalence of HIV in tuberculosis patients aged between 10 and 59 years receiving medical care at General Hospital Onitsha, Nigeria was investigated. Seventy-five of the patients were males while eight-five were females. Their sputum and blood samples were screened for tuberculosis and HIV. The sputum samples were examined by microscopy and culture. Patients between 20 and 29 years of age had the highest number of tuberculosis cases $(30.7 \%)$ while those aged between 50 and 59 years had the least number of cases (9.4\%). Forty-five males $(28.1 \%)$ and fifty females $(31.2 \%)$ tested positive to HIV respectively. The prevalence of HIV among the tuberculosis patients was $59.3 \%$. Twenty-eight patients $(29.5 \%)$ composed of twelve males $(12.6 \%)$ and sixteen females $(16.9 \%)$ between 20 and 29 years had TB/HIV while eleven patients $(11.6 \%)$ comprising six males $(6.3 \%)$ and five females $(5.3 \%)$ between 50 and 59 years were co-infected. Acid-fast bacilli were detected by culture in $92(57.5 \%)$ of the tuberculosis patients while they were detected by microscopy in 68 $(42.3 \%)$ of the patients indicating the higher sensitivity of culture for tuberculosis case detection.
\end{abstract}

Keywords Prevalence, Human Immunodeficiency Virus, Tuberculosis, Patients, General Hospital

\section{Introduction}

Tuberculosis has been reported as the most common respiratory disease that results from the inhalation of air droplets infected with Mycobacterium tuberculosis, with the highest prevalence of the disease in Sahara Africa and Asia [1]. More than half of these live in countries ravaged by HIV/AIDS [2]. It is the commonest opportunistic infection and the number one cause of death in HIV patients in developing countries and accounts for about $40 \%$ of all manifestations seen in HIV patients [3]. About $25 \%$ to $65 \%$ of patients with HIV/AIDS have tuberculosis of any organ and tuberculosis accounts for about $13 \%$ of all HIV related deaths worldwide $[4,5]$.

Between 1998 and 1999, a 20\% increase of tuberculosis case was reported in countries severely affected by HIV/AIDS in Africa [6]. People with HIV are increasingly infected with tuberculosis because HIV weakens their immune system. Autopsy studies have shown disseminated tuberculosis in $14 \%$ to $54 \%$ of HIV infected people in HIV prevalent countries, many of whom were undiagnosed prior to death [7]. Also, studies among HIV-positive persons attending voluntary counseling and testing and in home-based HIV/AIDS care patients have consistently reported high rates of undiagnosed prevalent tuberculosis $[8,9]$.

Individuals infected with tuberculosis have a higher likelihood of progressing from intent tuberculosis to active tuberculosis if they are co-infected with HIV [10]. Furthermore, tuberculosis may speed the development of HIV infection to AIDS in dually-infected individuals. Tuberculosis and HIV co-morbidity is a relevant public health issue worldwide and does not spare the European region [11-13].

HIV positive individuals infected with Mycobacterium tuberculosis are placed at a 20-30 times greater risk of developing active TB [14]. Diagnosis of latent infection and active TB is more challenging in immuno-compromised individuals including people living with HIV [2]. They may present with a typical clinical manifestation of TB or have masked disease with implications on adequate clinical case management $[2,15]$.

The objective of this study was to determine the prevalence of HIV in tuberculosis positive patients in General Hospital Onitsha, Nigeria. The result will assist physicians in the treatment and care of infected persons as 
well as add to the local data on patients with such infections in the area.

\section{Materials and Methods}

\subsection{Collection of Samples}

Sputum samples were collected from one hundred and sixty tuberculosis positive patients ( 75 males and 85 females) aged between 10 and 59 years in sterile capped containers from March 2014 and June 2015. Prior to collection, the sex and age of each of the patients were obtained from their corresponding medical records. Blood samples were collected through Venipuncture. The arms of the patients were tied with a tourniquet and the veins disinfected using swabs soaked in methylated spirit. Different sterile disposable needles and $2 \mathrm{ml}$ syringes were used for the samples collection. Each blood sample was transferred aseptically into a microtitre tube containing Ethylene diamine tetra-acetic acid (anticoagulant). The samples were thereafter transferred to the microbiology laboratory of Nnamdi Azikiwe University Awka, Nigeria for analysis.

\subsection{Microscopic Examination of the Sputum Samples}

The sputum samples were analyzed in a biosafety cabinet for the presence of acid-fast bacilli using Ziehl-Neelsen staining technique. Smears of the sputum samples were made on clean grease-free slides and allowed to air dry. The air-dried smears were covered with carbolfuschin, steamed for five minutes and decolourized with acid-alcohol for twenty seconds after cooling. The slides were rinsed with water and stained with methylene blue and allowed to stay for thirty seconds. The stained slides were blotted, allowed to air dry and examined under the oil immersion lens of the microscope.

\subsection{Culture Procedure of the Sputum Samples}

The sputum samples were evenly spread on the entire surface of Lowenstein-Jensen agar slopes and subsequently incubated at $37^{\circ} \mathrm{C}$. The slopes were observed for growth for sixty-three days. All slopes that did not show any growth within this period were recorded as being acid-fast negative and discarded. Smears of the colonies that grew were made, stained by Ziehl-Neelsen technique and examined for the presence of acid-fast bacilli.

\subsection{Human Immunodeficiency Virus Screening}

Five milliliters of the blood samples were introduced into a test tube and centrifuged at 60 revolutions per minutes for 30 minutes. The supernatant serum was collected and analyzed using the Abott Determine HIV-1 and HIV-2 test kits. $50 \mu 1$ of the serum sample was applied to the sample pad of the test kits using a micropipette and the kits left to stand for fifteen minutes at room temperature. The appearance of a red bar in both the control and patient windows of the kits was a positive result while the appearance of a red bar in the control window of the kits only was a negative result.

\subsection{Data Analysis}

The data were analyzed using SPSS 19.0 window packages. The significance of the prevalence of HIV in the tuberculosis positive patients was determined by Chi square test at $\mathrm{P}<0.05$.

\section{Results}

The distribution of the tuberculosis positive patients according to age and sex is presented in Table 1 . The highest numbers of the tuberculosis patients $(30.7 \%)$ were within the age group of 20-29 years while the lowest numbers $(9.4 \%)$ of the tuberculosis patients were within the age group of 50-59 years.

Table 1. Distribution of the Tuberculosis Positive Patients According to Age and Sex

\begin{tabular}{cccc}
\hline $\begin{array}{c}\text { Age Group } \\
\text { (Years) }\end{array}$ & Male (\%) & Female (\%) & Total (\%) \\
\hline $10-19$ & $13(8.1)$ & $19(11.8)$ & $32(19.9)$ \\
$20-29$ & $23(14.4)$ & $26(16.3)$ & $49(30.7)$ \\
$30-39$ & $18(11.3)$ & $23(14.4)$ & $41(25.7)$ \\
$40-49$ & $12(7.5)$ & $11(6.8)$ & $23(14.3)$ \\
$50-59$ & $9(5.6)$ & $6(3.8)$ & $15(9.4)$ \\
Total & $75(46.9)$ & $85(53.1)$ & $160(100.0)$ \\
\hline
\end{tabular}

The HIV status of the tuberculosis patients according to sex is shown in Table 2. Forty-five of the male tuberculosis patients $(28.1 \%)$ were HIV positive while fifty of the female tuberculosis patients (31.2\%) tested positive to HIV.

Table 2. HIV Status of the Tuberculosis Positive Patients According to Sex

\begin{tabular}{cccc}
\hline Sex & HIV + ve $(\%)$ & HIV-ve $(\%)$ & Total (\%) \\
\hline Male & $45(28.1)$ & $30(18.8)$ & $75(46.9)$ \\
Female & $50(31.2)$ & $35(21.9)$ & $85(53.1)$ \\
Total & $\mathbf{9 5 ( 5 9 . 3 )}$ & $\mathbf{6 5 ( 4 0 . 7 )}$ & $\mathbf{1 6 0 ( 1 0 0 . 0 )}$ \\
\hline
\end{tabular}

The distribution of TB/HIV co-infected patients according to age and sex is presented in Table 3. Twenty-eight of the tuberculosis patients $(29.5 \%)$ between the age group of 20-29 years, comprising twelve males $(12.6 \%)$ and sixteen females $(16.9 \%)$ tested positive to the virus while eleven of the tuberculosis patients $(11.6 \%)$ between the age group of $50-59$ years and comprising six males (6.3\%) and five females (5.3\%) had the human immunodeficiency virus. 
Table 3. Distribution of TB/HIV Co-infected Patients According to Age and Sex

\begin{tabular}{cccc}
\hline $\begin{array}{c}\text { Age Group } \\
\text { (Years) }\end{array}$ & Male (\%) & Female (\%) & Total (\%) \\
\hline $10-19$ & $10(10.5)$ & $12(12.6)$ & $22(23.1)$ \\
$20-29$ & $12(12.6)$ & $16(16.9)$ & $28(29.5)$ \\
$30-39$ & $9(9.5)$ & $10(10.5)$ & $19(20.0)$ \\
$40-49$ & $8(8.4)$ & $7(7.4)$ & $15(15.8)$ \\
$50-59$ & $6(6.3)$ & $5(5.3)$ & $11(11.6)$ \\
Total & $45(47.3)$ & $50(52.7)$ & $95(100.0)$ \\
\hline
\end{tabular}

The detection of acid-fast bacilli by culture and microscopy in the tuberculosis patients is shown in Table 4. The bacilli were detected by culture in $92(57.5 \%)$ of the tuberculosis patients while they were detected by microscopy in $68(42.5 \%)$ of the patients.

Table 4. Detection of Acid-Fast Bacilli by Culture and Microscopy in the Tuberculosis Patients

\begin{tabular}{cc}
\hline Method & $\begin{array}{c}\text { Number of Tuberculosis Positive } \\
\text { Patients (\%) }\end{array}$ \\
\hline Culture & $92(57.5)$ \\
Microscopy & $68(42.5)$ \\
Total & $160(100.0)$ \\
\hline
\end{tabular}

\section{Discussion}

One hundred and sixty tuberculosis positive patients in General Hospital Onitsha, Nigeria were used for the study. The prevalence rate of tuberculosis was higher in the females than in the males (Table 1). This result is in agreement with the report of Onubogu et al [16]. The difference in the prevalence rate may be due to the reduced immunity in females.

The prevalence of tuberculosis was more $(30.7 \%)$ in the patients aged between 20 and 29 years, comprising twenty males $(14.4 \%)$ and twenty-six females $(16.3 \%)$. The prevalence was however the lowest $(9.4 \%)$ in the patients aged 50-59 years, made up of nine males (5.6\%) and six females $(3.8 \%)$. This result is in conformity with the reports of Nwobu et al [17] Umeh et al [18], Nwachukwu et al [19] and Onubogu et al [16] and indicated that the age group of 20-29 years is more vulnerable to tuberculosis infection than the other age groups.

Forty-five male tuberculosis patients $(28.1 \%)$ and fifty female tuberculosis patients $(31.2 \%)$ were HIV positive. The prevalence of HIV in the tuberculosis patients was $59.3 \%$ (Table 2). This result is in line with the works of Kwanjana et al [20] and Onubogu et al [16] supporting the high rates of TB/HIV Co-infections in high HIV prevalence population. The co-infection was higher in females $(31.2 \%)$ than in males $(28.1 \%)$. This may be because of early exposure of the females to sexual activity due to bad economic situations [18], lust for money and early marriage, high susceptibility to infection due to low immunity [18], delay in care seeking due to stigma associated with HIV infection [21], less access to fund for transportation and personal health care.

The age group of 20-29 years had the highest cases of TB/HIV co-infection (29.5\%) comprising of twelve males $(12.6 \%)$ and sixteen females $(16.9 \%)$ while the age group of 50-59 years had the lowest TB/HIV co-infection $(11.6 \%)$ made up of six males $(6.3 \%)$ and five females $(5.3 \%)$ (Table 3).

The patients were screened for acid-fast bacilli by both culture and microscopy. Acid-fast bacilli were detected by culture in $92(57.5 \%)$ of the patients while they were detected by microscopy in $68(42.5 \%)$ of the patients. This result is in agreement with the report of Onubogu et al [16] and Aderaye et al [22[. The result indicated the increased sensitivity of culture for the diagnosis of tuberculosis, hence the need for increased provision of culture facilities in tuberculosis laboratories in hospitals for efficient diagnosis of tuberculosis in both tuberculosis and TB/HIV co-infected patients.

\section{Conclusions}

Tuberculosis and Human Immunodeficiency Virus co-infection is a major cause of death worldwide. The high prevalence of HIV in the tuberculosis patients screened calls for increased attention in the area of diagnosis, treatment and care of the affected patients. All tuberculosis positive individuals must be screened for HIV and immediate treatment commenced on them. In addition, adequate laboratory facilities must be put in place for the prompt and efficient diagnosis of the co-infected patients.

\section{REFERENCES}

[1] D.A. Ojo, C.F. Mafiana, A. Adeniran-Sonola. Prevalence of Mycobacterium tuberculosis and Human Immunodeficiency Virus infections in Ogun State, Nigeria. Nigerian Journal of Parasitology. Vol.28, No.1, 39-43, 2007.http://dx.doi.org/10.4314/njpar.v28i1.37857

[2] S.K. Sharma, A. Mohan, T. Kadhiravan. HIV-TB Co-infection: Epidemiology, Diagnosis and Management. Indian Journal of Medical Research. Vol.121, No.4, 550-567, 2005. http://icmr.nic.in/ijmr/ijmr.htm.

[3] J.W. Pape. Tuberculosis and HIV in the Caribbean: approaches to diagnosis, treatment and prophylaxis. Topics in HIV medicine. Vol.12, No.5, 144-149, 2004. http://www.ncbi.nlm.nih.gov/pubmed/15647610.

[4] S.K. Sharma, T. Kadhiravan, A. Banga, T. Goyal, I. Bhatia, P.K. Saha. Spetrum of Clinical disease in a series of 135 hospitalized HIV-infected patients from North India. BMC Infectious Diseases. Vol. 4, No. 52, 2004. doi:10.1186/1471-2334-4-52

[5] E.L. Corbett, S. Charalambous, V.M. Moloi, K. Fielding, A.D. Grant, C. Dye, K.M. De Cock, R.J. Hayes, B.G. Williams, G.J. Churchyard. Human immunodeficiency Virus and the Prevalence of undiagnosed tuberculosis in African Gold 
Miners. American Journal of Respiratory and Critical Care Medicine. Vol. 170, No.6, 673-679, 2004. http://www.ncbi.nlm.nih.gov/pubmed/15191919.

[6] P.Hino, C.B. dos Santos, T.C.S. Vila, J.N. Muniz, A. Monroe. Tuberculosis Patients Submitted to Supervised Treatment in Ribeirao Preto-Sao Paulo-Brazil.1998 and 1999. Revista-Latino-Americana de Enfermagem. Vol. 13, No.1, 27-31, 2005. DOI:10.1590/S0104-11692005000100005.

[7] M.D. Haileyeus-Getahun, M.A. Mark Harrington, M.D. Rick O' Brien, F.R.C.P. Paul Nunn. Diagnosis of Smear-negative pulmonary tuberculosis in people with HIV infection or AIDS in resource-constrained settings: informing urgent policy changes. The Lancet Vol.369, NO. 9578, 2042-2049, 2007. DOI:http://dx.doi.org/10.1016/S0140-6736 (07)60284-0.

[8] A.L. Burgess, D.W. Fitzgerald, P. Severe, P. Joseph, E. Noel, N. Rastogi, W.D. Johnson, Jr, J.W. Pape. Integration of tuberculosis screening at an HIV voluntary counseling and testing centre in Haiti.AIDS.Vol.15, No.14, 1875-1879,2001. DOI:10.1097/00002030-200109280-00018.

[9] M.E. Kimerling, J. Schuchter, E. Chanthol, T. Kunthy, F. Stuer, P. Glaziou, O. Ee. Prevalence of Pulmonary tuberculosis among HIV-infected persons in a home care program in Phnom Penh Cambodia. International Journal of Tuberculosis and Lung Disease. Vol.6, No.11, 988-994 (7), 2002. http://www.ingentaconnect.com/content/iuatid/ijtld/2002/00 000006/00000011.

[10] A.B. Ahmed, T. Abubakar, V. Delpech, M. Lipman, D. Boccia, J. Forde, D. Antoine, J.M. Watson. The growing Impact of HIV infection on the epidemiology of tuberculosis in England and Wales: 1999-2003. Thorax, Vol.62, No.8, 672-676,2007. DOI:10.1136/thx.2006.072611.

[11] E. Pontali, M.B. Pasticci, A. Matteelli, F. Baldelli, G.B. Migliori. Tuberculosis and HIV Co-infection. Do we have a Surveillance System in Europe? European Respiratory Journal. Vol. 38, No. 6, 1258-1260, 2011. doi:10.1182/09031936.00143111.

[12] J.V. Lazarus, M. Olsen, L. Ditiu, S. Matic. Tuberculosis-HIV co-infection: Policy and epidemiology in 25 countries in the WHO European region HIV Medicine. Vol. 9, No.6, 406-414, 2008. DOI: $10.1111 /$ j.1468-1293.2008.00567.x

[13] E.L. Corbett, C.J. Watt, N. Walker, D. Maher, B.G. Williams, M.C. Raviglione, C. Dye. The growing burden of tuberculosis: global trends and interactions with the HIV epidemic. Archives of Internal Medicine. Vol. 163, No.9, 1009-1021, 2003. doi: 10.1001/archinte.163.9.1009.

[14] L. Aaron, D. Saadoun, I. Calatroni, O. Launay, N. Memain, V. Vincent, G. Marchal, B. Dupont, O. Bouchaud, D. Valeyre, O. Lortholary. Tuberculosis in HIV-infected Patients: a comprehensive review. Clinical Microbiology and Infection, Vol. 10, No.5, 388-398, 2004. doi: 19.1111/J.1469-0691.2004.00758.x.

[15] B.C. De Jong, D.M. Isrealski, E.L. Corbett, P.M, Small. Clinical Management of tuberculosis in the context of HIV infection. Annual Review of Medicine. Vol.55, 283-301, 2004. DOI: 10.1146/annurev.med.55.091902.103753.

[16] C.C. Onubogu, C.N. Kunle-Ope, N. Onyejepu, N.K. Nwokoye, T.Y. Raheem, U.T. Igbasi, N.E. Tochukwu, R.M. Omoloye, C.O. Ejezie, Z. Musa, N.N. Odunukwe, D.I. Onwujekwe, E.O. Idigbe. Prevalence of tuberculosis and human immunodeficiency virus (TB/HIV) Co-infections amongst patients with bronchopulmonary disorders in Lagos. African Journal of Microbiology Research. Vol. 4, No. 18, 1904-1908, 2010. http://www.researchgate.net/publication/228363427.

[17] G.O. Nwobu, M.A. Okodua, Y.M. Tatfeng. Comparative Study of HIV-Associated Pulmonary Tuberculosis in Chest Clinics from two regions of Edo State, Nigeria. Online Journal of Health and Allied Sciences. Vol.3, No.3, 4, 2004. http://www.ojhas.org/issue11/2004-3-4.htm.

[18] E.U. Umeh, D. Ishaleku, C.C. Iheukwumere. HIV/ Tuberculosis Co-infection Among Patients Attending a Referral Chest Clinic in Nasarawa State, Nigeria. Journal of Applied Sciences. Vol.7,933-935,2007. DOI:10.3923/jas.2007.933.935.

[19] N.C. Nwachukwu, A. Orji, I. Kanu, H.C. Okereke. Epidemiology of Pulmonary Tuberculosis in some parts of Abia State, Federal Republic of Nigeria. Asian Journal of Epidemiology. Vol. 2, No.1, 13-19, 2009. DOI:10.3923/aje.2009.13.19.

[20] J.H. Kwanjana, A.D. Harries, F. Gausi, D.S. Nyangulu, F.A. Salaniponi. HIV Seroprevalence in patients with tuberculosis in Malawi. Malawi Medical Journal. Vol. 13, No.1, 7-10, 2001.

http://www.ajo/info.index.php/mmj/article./view/10842.

[21] P. Nsubuga, J.L. Johnson, A. Okwera, R.D. Mugerwa, J.J. Ellner, C.C. Whalen. Gender and HIV-associated pulmonary tuberculosis: Presentation and outcome at one year after beginning anti tuberculosis treatment in Uganda. BMC Pulmonary Medicine. Vol. 2, 4, 2002. doi: 10.1186/1471-2466-2-4.

[22] G. Aderaye, H.G. Egziabher, A. Aseffa, A. Worku, L. Lindquist. Comparison of acid-fast stain and culture for Mycobacterium tuberculosis in Pre-and Post-bronchoscopy sputum and bronchoalveolar lavage in HIV-infected patients with atypical Chest X-ray in Ethiopia. Annals of Thoracic Medicine. Vol. 2, No. 4, 154-157, 2007. DOI: 10.4103/1817-1737.36549. 